\title{
Building preservation awareness
}

\author{
By Diane Kaufman
}

\section{Use visual aids and bumor to make your point}

$\mathbf{H}$ ow do you stress the importance of caring for materials that are circulating from your library? The Preservation Unit of Virginia Tech Libraries may have found an answer. And the answer was right in our own backyard!

During the second week of October last year, the Preservation Unit gave a two-day demonstration in the lobby of the main library. We placed several tables in the lobby on which we put the assorted supplies we use to do our various repairs. We gave patrons a firsthand look at what we do in the Preservation Unit. It was also a chance for our visitors to ask how they might take better care of the library's collection as well as their own library.

\section{Creating a visual impact}

Prior to the exhibit, we had spent several days taking photographs of student workers doing their various jobs in the unit. The students made a large poster using the photos, which helped all to understand the variety of the daily tasks they do. To enhance the impact of the photographs, we decided to compile some statistics that would make everyone stop and think about taking proper care of the university's materials. Whatever we were going to do had to have a personal effect on each patron who looked at the display. We had to make people understand that when the collection is misused in any way, the results do affect their pocketbooks. As we looked around at books to be discarded because of disrepair, books with pages cut from them, and ones that had the complete text removed, our student workers began to ask ques- tions. Soon we had more ideas than we ever expected. And we had the hard-hitting information we were seeking! We developed a series of posters to create a visual impact.

Why are tuition costs rising? was one question on a poster. We learned that the average cost of a book is about $\$ 40$. One must remember that science books may be much more expensive than a novel, but we wanted an average figure. We were able to acquire this with the help of some of the people in our Technical Services Department. With this dollar

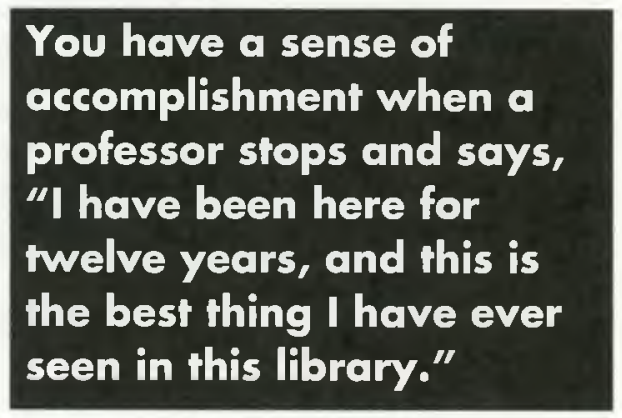

amount, we considered the 40 books we had just discarded in the previous month. We displayed the photo of one of our students next to these 40 books, prominently stacked on a desk. Some of these books had the usual problems: too much writing in them or a cover from which the text was totally removed. However, there was the unusual, such as the reserve book that left the library for two hours. This was enough time, however, for the patron's cat to relieve itself on the book. (We wrapped this one in a plastic bag!) We now had exactly the information we needed ... . and many people stopped and commented on the statistics outlined on poster 1 . 
One reason our tuition costs rise is the cost of replacing library materials.

We have to discard many books each year because of lost text, damage, etc.

In September 1994 alone, we discarded forty books.

To replace these forty books would equal a semester's cost for one in-state fuition.

Poster 1

\section{Making the point with humor}

Is there a pattern to removal of pages from books by library users? Since we keep a listing of all books from which pages are removed, this was an easy question to answer. These answers led us to develop two posters. These became the highlight of the demonstration and the messages are shown on poster 2 .

The comments and smiles of definite understanding were what we needed! (Sometimes a humorous message is better than one that preaches.)

Are there journals or books from which people more readily steal? We looked over our records and made one last poster (poster 3) which, again, made a point with humor. Of course, the latter title brought many laughs.

\section{Did you know}

more people take pages out of books about

\section{Education}

Engineering

Psychology

than any other topics? AND

If we want to conserve trees, $\mathbf{D O N}$ 'T take pages from

\section{The Timber Producer}

or

\section{American Forests}

as more trees must be cut down to replace these pages.

\section{There is something very wrong}

when pages are removed from these particular joumals or books:

Governance

Urban Lawyer

Addicfive Behavior

Ethics in Engineering

Crimes \& Punishment

The Journal of Business Ethics

Journal of Research in Crime \&

Delinquency

Robin Hood

Poster 3

\section{There's nothing like success!}

Our demonstrations were successful and our posters were thought-provoking. We knew we were a success when we saw the large numbers of people who stopped to read our visual aids, strategically placed in the lobby. But, had it not been for our primary patrons, our own university student assistants, and their questions, we would not have been as successful as we were. They were our key to success.

You have a sense of accomplishment when a professor stops and says, "I have been here for twelve years, and this is the best thing I have ever seen in this library."

\section{There's still time to bid on two silent auction items}

American Book Prices Current is offering an updated CD-ROM with auction sales reported in ABPC (1975-1994). Covering 19 volumes in over a half million records, the $\mathrm{CD}$ contains the sales of autographs, manuscripts, documents, books, maps, and broadsides worldwide. The regular price for this CD-ROM is $\$ 2,000$; minimum bid is $\$ 600$.

OCLC is offering a six-month subscription to the FirstSearch base package which includes single port access to WorldCat, ArticleFirst, ContentsFirst, FastDoc, MEDLINE, and other databases. The regular rate for this is $\$ 2,750$; minimum bid is $\$ 750$.

To bid call Jack Briody at (800) 545-2433, ext. 2516; e-mail: jack.briody@ala.org. Bids will only be accepted in $\$ 75$ increments. Bidding will continue through ALA Midwinter. 


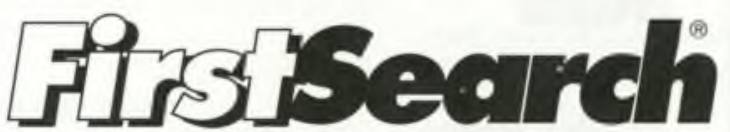

A world of information online

\section{THE FASTEST GROWING}

END-USER DATABASE SERVICE

\section{IN THE LIBRARY COMMUNITY}

- Full-text and Images* Online

- Web Access*

- NetFirst ${ }^{\mathrm{T} \text { ***}}$ the authoritative guide to Internet resources

- WorldCat ${ }^{\mathrm{TM}}$ the end-user version of the OCLC Online Union Catalog

- More than 50 databases

To find out how FirstSearch ${ }^{\star}$ can help you move to the next stage of the electronic library:

Call us at 1-800-848-5878, ext. 6425 to request a copy of

the new FirstSearch brochure. Or view and order it online through our home page on the World Wide Web:

bttp://www.oclc.org

"Coming soon

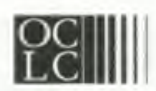

FURTHERING ACCESS TO THE WORLD'S I NFORMATION 